\title{
Association of Microvessel Density with Infiltrating Cells in Human Cutaneous Malignant Melanoma
}

\author{
Judit KISS, ${ }^{1}$ József TÍMÁR, ${ }^{1}$ Beáta SOMLAI, ${ }^{4}$ Katalin GILDE, ${ }^{2}$ Zsuzsanna FEJŐS, ${ }^{2}$ István GAUDI, ${ }^{3}$ Andrea LADÁNYI ${ }^{1}$ \\ Departments of ${ }^{1}$ Tumor Progression and ${ }^{2}$ Dermatology, and ${ }^{3}$ National Cancer Registry, National Institute of Oncology, \\ ${ }^{4}$ Institute of Dermato-Venerology and -Oncology, Semmelweis University, Budapest, Hungary
}

Vascularization and host response to malignant
tumors may have common molecular regulators,
therefore, we analyzed the relationship between
microvessel density (MVD) and tumor infiltrating
cells in cutaneous malignant melanoma. Density of
lymphocyte subpopulations, macrophages, dendrit-
ic cells and CD34 microvessels was determined by
immunohistochemistry in primary tumor samples
from fifty-two patients with melanoma thicker than
1 mm. Intratumoral MVD did not show significant
association with infiltration for any of these cell
types. In the case of peritumoral reactive cell densi-
ties analyzed in the whole patient population, a
positive correlation of MVD was found with CD $3^{+}$
T cell density. This association was stronger in
melanomas $>4.0$ mm and in visceral metastatic tumors. In these subgroups similar phenomenon was observed for $\mathrm{CD}^{+}$cells. We found significant correlation of MVD with $\mathrm{CD}^{+} 8^{+}$macrophage density only in the highest thickness category, and weak associations with B-cell and dendritic cell infiltration in visceral metastatic cases. MVD did not vary significantly in tumors categorized according to thickness, localization, ulceration or histological type. However, both intratumoral MVD and macrophage infiltration were significantly higher in male patients compared to females. The correlation of immune cell density with tumor vascularization and gender differences in vascularity and macrophage infiltration of melanoma deserve further attention. (Pathology Oncology Research Vol 13, No 1, 21-31)

Key words: angiogenesis, immunohistochemistry, lymphocytes, macrophages, microvessel density

\section{Introduction}

Vascularization of cancers was long thought to be provided by neoangiogenesis and active ingrowth of new vessels into the tumor tissue. ${ }^{3}$ However, it became clear that vascularization of various cancer types could be funda-

Received: Jan 17, 2007; accepted: Febr 12, 2007

Correspondence: Andrea Ladányi, Department of Tumor Progression, National Institute of Oncology, 7-9 Ráth Gy. u., Budapest, H-1122, Hungary. Tel: (36) (1) 224-8600; fax: (36) (1) 224-8706; E-mail: ladanyi@oncol.hu

Abbreviations: MVD, microvessel density; VEGF, vascular endothelial growth factor; bFGF, basic fibroblast growth factor; TGF, transforming growth factor; TNF, tumor necrosis factor; IL, interleukin; MMP, matrix metalloproteinase; DC, dendritic cell; SSM, superficial spreading melanoma; NM, nodular melanoma; ALM, acral lentiginous melanoma; LMM, lentigo maligna melanoma mentally different since beside neoangiogenesis there are several alternative mechanisms that are able to provide appropriate blood supply. These alternative mechanisms are: cooption of preexisting normal vessels, postnatal angiogenesis, glomeruloid angiogenesis and vasculogenic mimicry, all regulated by pro- and anti-angiogenic factors. ${ }^{17}$ Vascularization of malignant melanoma is relatively unique since it is provided by cooption of preexisting normal and newly formed peritumoral vessels. During the incorporation phase (tumor tissue expansion), only a small proportion of these microvessels survive in the intratumoral microenvironment. ${ }^{18}$ The literature is highly controversial concerning the association of microvessel density (MVD) and clinicopathological parameters of malignant melanoma. Several investigators have suggested a relationship between the extent of tumor vascularity and poor prognosis. ${ }^{15,29,43,59}$ However, others found that tumor vascularity was not of prognostic value in this tumor type, or 
even came to the conclusion that high vascularization was associated with a better prognosis. ${ }^{8,25}$

Melanoma is considered one of the most immunogenic tumors, and is a preferential target of experimental immunotherapeutic protocols. The existence of melanomaassociated antigens and the detection of T lymphocytes recognizing these antigens, both systemically and at the tumor sites, provide evidence that antitumor immune reactions can develop in melanoma patients. However, as tumor progression is often seen in the presence of a substantial lymphocytic infiltration, this immune response is apparently incapable of controlling tumor growth, probably due to multiple mechanisms resulting in tumor escape. ${ }^{44,64}$

As the presence of immune cells in a tumor does not guarantee the development of an efficient immune reaction, the degree of their infiltration does not necessarily correlate with the intensity of antitumor immune response. Further complicated by the different sensitivity of individual tumors to immune effector mechanisms, this could influence the role of mononuclear cell infiltration in the progression of tumors. Moreover, the prognostic importance of the different infiltrating cell types is frequently controversial, which may partly be due to their multiple functions, as discussed below.

Since the majority of tumor-infiltrating cells derive from the circulation, one might expect an association between the density of microvessels and that of infiltrating cells in a tumor. Another reason for such an association could be that tumor-infiltrating host cells are rich sources of angiogenic factors.

Macrophages are one of the predominant types of cells infiltrating human melanomas. They can play a role in the destruction of tumors via their antigen presenting activity as well as via direct tumor cell killing by the production of toxic factors as tumor necrosis factor-alpha (TNF- $\alpha$ ), NO or $\mathrm{H}_{2} \mathrm{O}_{2} \cdot{ }^{42,45}$ On the other hand, macrophage-derived factors may suppress the immune reactions and stimulate tumor cell proliferation and invasiveness. ${ }^{32,42}$ These cells are also one of the key producers of angiogenic factors including vascular endothelial growth factor (VEGF), basic fibroblast growth factor (bFGF), transforming growth factor-alpha (TGF- $\alpha$ ), platelet-derived endothelial cell growth factor/thymidine phosphorylase (PDECGF/TP) and interleukin-8 (IL-8). ${ }^{31,40,60}$ Macrophages are also able to transform the extracellular matrix either by the direct secretion of degradative enzymes or by extracellular matrix-modulating cytokines. ${ }^{48}$ Torisu et al suggested the possible involvement of TNF- $\alpha$ and IL- $1 \alpha$ secreted by macrophages in the neovascularization of melanoma. ${ }^{61}$ Infiltration by macrophages has been shown to correlate with vascularization in several tumor types, ${ }^{24,37,41,49}$ however, other studies found no such association. ${ }^{14,33,62}$ Unlike in other tumor types, ${ }^{24,33,37,41}$ a prognostic role of macrophage infiltration was not confirmed in cutaneous melanoma. ${ }^{50}$
Beside macrophages, T lymphocytes are often major components of tumor infiltrates in many solid tumors, and their central role in antitumor immunity is well established. However, tumor-infiltrating $\mathrm{T}$ cells have been shown to be functionally defective, incompletely activated or anergic. ${ }^{47,63}$ Therefore, for the characterization of immune competent cells in tumor infiltrates, it is important to determine their functional and activation state. In malignant melanoma, published results on the pathophysiological role of lymphoid infiltrate (mostly $\mathrm{T}$ lymphocytes) are controversial: while some studies found prominent lymphocytic infiltrate a sign of good prognosis, ${ }^{9,10}$ others showed no significant correlation. ${ }^{5}$ In our study evaluating $\mathrm{T}$ cells expressing the activation markers CD25 and OX40, high peritumoral density of activated T lymphocytes proved a predictor of favorable disease outcome. ${ }^{35}$ Beside their immunological role, $\mathrm{T}$ cells may also be involved in vascularization processes of tumors. Qin et al has demonstrated that IFN- $\gamma$-mediated angiostasis was the primary mechanism of $\mathrm{CD} 8^{+}$effector $\mathrm{T}$ cells in mediating tumor rejection in mouse models. ${ }^{53}$ On the other hand, production of VEGF by tumor-infiltrating $\mathrm{T}$ cells has been described, which could play a role in tumor angiogenesis. $^{21}$

Dendritic cells (DCs), as the most potent antigen presenting cells, play key roles in antitumor immune responses. DCs efficiently capture and process tumor antigens, migrate and then reach local lymph nodes, where they activate antigen-specific T lymphocytes. The presence of dendritic cells in tumors has been associated with better prognosis in patients with various cancers. ${ }^{26-28,55}$ In our study on human cutaneous melanoma patients, high peritumoral density of mature DCs expressing the DC-LAMP marker was associated with significantly better prognosis. ${ }^{34}$ On the other hand, several studies have indicated that VEGF inhibits the maturation and function of dendritic cells, and its expression negatively correlated with DC density in tumors. ${ }^{22,26,55}$ VEGF is thus suggested to be associated not only with the enhancement of angiogenesis, but also with a decline of local immune response in tumors. Recently, it has been shown in ovarian carcinoma that tumor-associated plasmacytoid DCs are able to induce angiogenesis in vivo by producing TNF- $\alpha$ and IL- 8 , while myeloid DCs caused suppression through IL-12 secretion. ${ }^{13}$ Furthermore, DC precursors were demonstrated to express both endothelial and dendritic cell markers, and to be capable of assembling into blood vessels. ${ }^{12}$

In the present study we analyzed the relationship among MVD and tumor-infiltrating cells by immunohistochemistry in primary human cutaneous malignant melanoma. We also investigated the possible associations of tumor thickness, ulceration, localization, clinical outcome and patients' sex with the density of the major infiltrating cell types that were shown to be correlated with vascularization. 


\section{Materials and methods}

\section{Patients}

Archival tissue samples were obtained from 52 patients with primary cutaneous malignant melanoma, who underwent surgery between 1980 and 2000 at the Institute of Dermato-Venerology and -Oncology, Semmelweis University, and at the National Institute of Oncology, Budapest. The study was approved by the ethics committees of both institutions. None of the patients received any anticancer treatment prior to surgery. Clinical and pathological characteristics are summarized in Table 1 . The depth of invasion according to Clark ranged from level II to level V, and Breslow index ranged from 1.1 to $9.9 \mathrm{~mm}$. The tumors were grouped into three thickness categories based on the current AJCC (American Joint Committee on Cancer) staging system ${ }^{4}(1.01-2.0 \mathrm{~mm}$, 2.01-4.0 mm, $>4.0 \mathrm{~mm}$ ), and into three categories according to disease progression during the 5-year follow-up period (nonmetastatic, lymph node metastatic, visceral metastatic). Nineteen patients had not developed metastases during the follow-up period, while eight patients had regional lymph node metastases only, which were excised. Twenty-five patients had developed distant visceral metastases. The 5-year survival of patients in both the nonmetastatic and the lymph node metastatic groups was $100 \%$, while only one patient developing distant visceral metastases survived for more than 5 years (62 months); no patients died of melanoma-unrelated causes during the 5-year follow-up period. Tumors with clinical regression and/or histological signs of late regression were not included in the study.

Immunohistochemical detection of infiltrating cells and microvessels in melanoma samples

Sections of $3 \mu \mathrm{m}$ cut from formalin-fixed, paraffinembedded cutaneous melanoma samples were used in the study. Immunohistochemistry was performed on deparaffinized serial sections after microwave antigen retrieval. Endogenous peroxidase activity was blocked with incubation of the slides in $3 \% \mathrm{H}_{2} \mathrm{O}_{2}$ in methanol, and non-specific binding sites were blocked with $3 \%$ bovine serum albumin. Polyclonal anti-CD3 (diluted 1:100), monoclonal anti-CD8 (diluted 1:100), anti-CD20 (diluted 1:100), anti-CD34 (diluted 1:50) and anti-CD68 (diluted 1:100) (all from Dako, Glostrup, Denmark) and monoclonal anti-CD1a (Immunotech, Marseilles, France) were used as primary antibodies, and mouse IgG1 (Sigma, St. Louis, MO) for negative control. Biotinylated anti-mouse/antirabbit Ig was used as secondary reagent, followed by streptavidin-peroxidase treatment (LSAB2 System, HRP; Dako). Antibody binding was visualized with 3-amino-9ethylcarbazole (AEC; Vector Laboratories, Inc., Burlingame, CA), then the slides were counterstained with hematoxylin.

Table 1. Patient and tumor characteristics

\begin{tabular}{|c|c|c|c|c|}
\hline Patient group & All patients & Nonmetastatic & LN metastatic & Visceral metastatic \\
\hline \multicolumn{5}{|l|}{ Sex } \\
\hline Male & 24 & 8 & 4 & 12 \\
\hline Female & 28 & 11 & 4 & 13 \\
\hline \multicolumn{5}{|l|}{ Localization } \\
\hline Extremities & 21 & 8 & 3 & 10 \\
\hline Trunk & 29 & 11 & 5 & 13 \\
\hline Head & 2 & 0 & 0 & 2 \\
\hline \multicolumn{5}{|l|}{ Type } \\
\hline SSM & 30 & 11 & 4 & 15 \\
\hline NM & 19 & 7 & 3 & 9 \\
\hline ALM & 2 & 1 & 1 & 0 \\
\hline LMM & 1 & 0 & 0 & 1 \\
\hline \multicolumn{5}{|l|}{ Thickness (mm) } \\
\hline $1.01-2.0$ & 13 & 5 & 3 & 5 \\
\hline $2.01-4.0$ & 23 & 9 & 3 & 11 \\
\hline$>4.0$ & 16 & 5 & 2 & 9 \\
\hline \multicolumn{5}{|l|}{ Ulceration } \\
\hline Present & 35 & 11 & 5 & 19 \\
\hline Absent & 17 & 8 & 3 & 6 \\
\hline 5-year survival & $28 / 52(54 \%)$ & $19 / 19(100 \%)$ & $8 / 8(100 \%)$ & $1 / 25(4 \%)$ \\
\hline
\end{tabular}

LN metastatic: only regional lymph node metastases during the follow-up period (5 years), SSM: superficial spreading melanoma; NM: nodular melanoma; ALM: acral lentiginous melanoma; LMM: lentigo maligna melanoma 


\section{Evaluation of the immune reactions}

Slides were examined using a graticule of $10 \times 10$ squares, calibrated as $0.25 \mathrm{~mm}^{2}$ at $200 \mathrm{x}$ magnification. Counting was performed by two investigators (J.K., A.L.), both blinded to the clinical information. Blood vessels
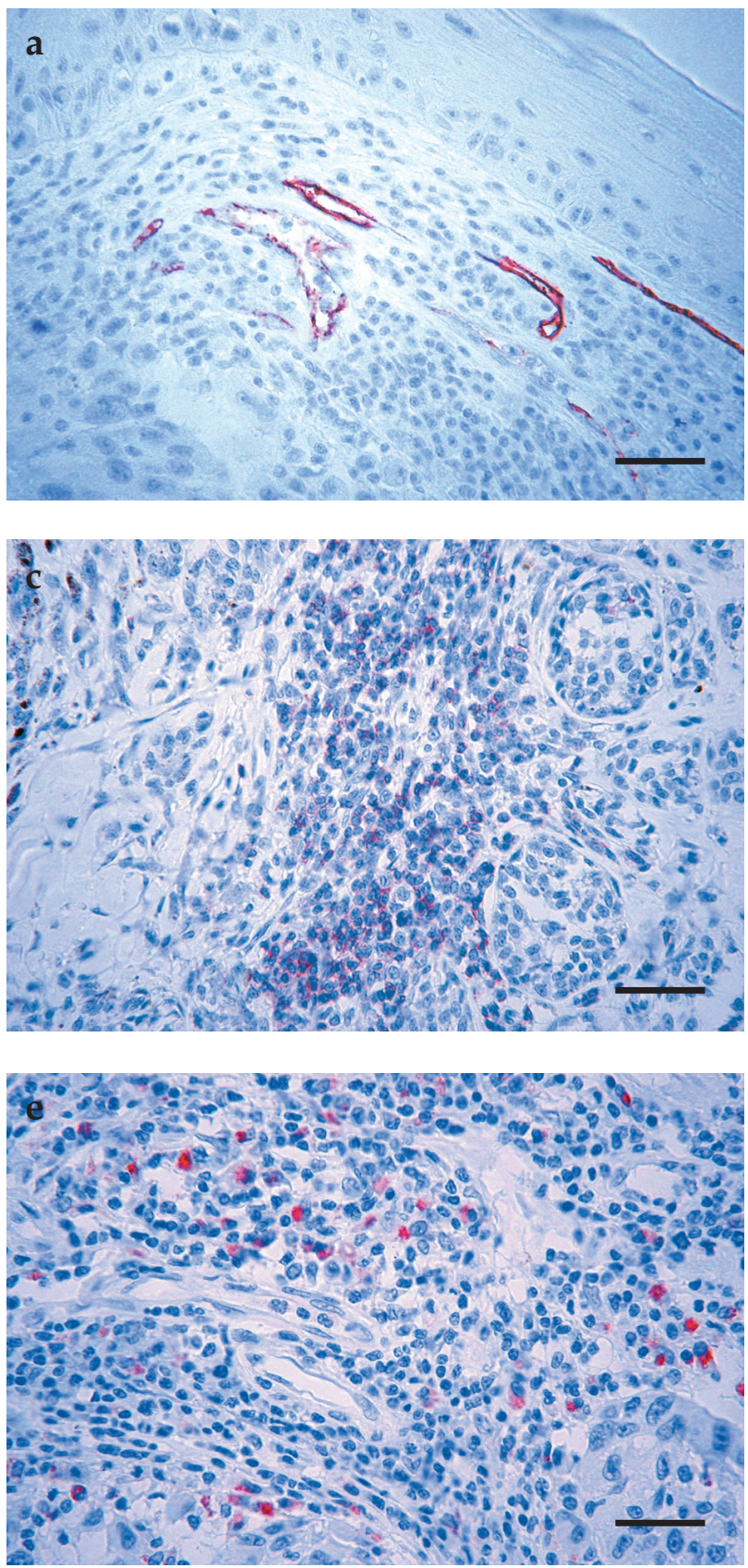

were highlighted by staining endothelial cells with antiCD34 antibody. Any red-staining endothelial cell cluster that was clearly separate from adjacent microvessels, tumor cells, and other connective tissue elements was considered a single, countable microvessel (Fig. la,b). Vessel lumens were not necessary for a structure to be defined as
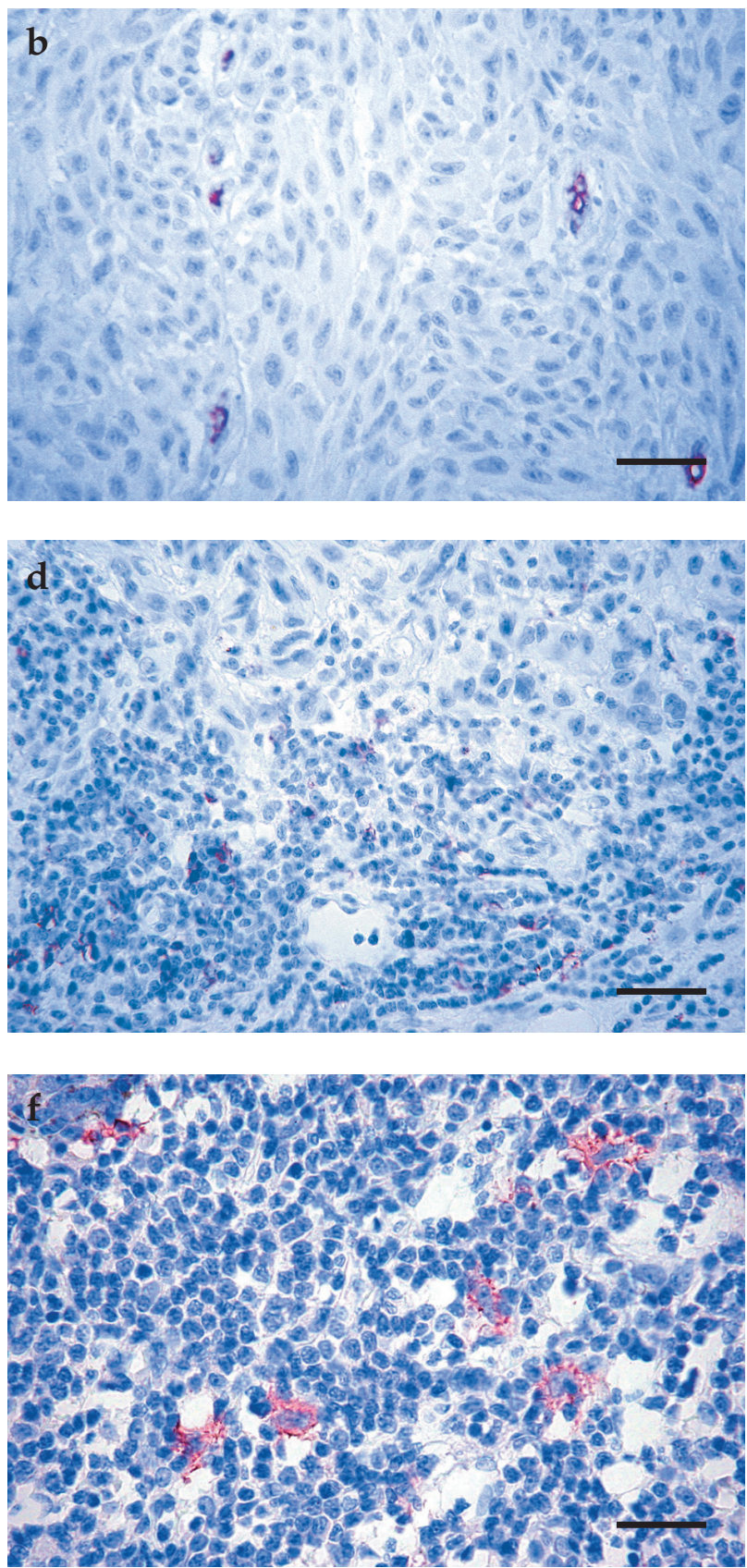

Figure 1. Immunohistochemistry of microvessels and infiltrating cells in cutaneous melanoma. Visualization of peritumoral (a) and intratumoral (b) microvessels using CD34 marker (red signal). (c) Identification of T lymphocytes in peritumoral infiltrate by CD3 marker (red). Note that the majority of the peritumoral infiltrate is composed of T cells. (d) Identification of B cells in the peritumoral infiltrate of melanoma using CD20 marker (red). (e) Identification of macrophages in peritumoral infiltrate of melanoma using CD68 marker (cytoplasmic red signal). (f) Identification of dendritic cells in the peritumoral infiltrate using CD1a marker (red signal). Note the low density of dendritic cells in the infiltrate. Bar $=100 \mu \mathrm{m}$. 
Table 2. Correlations of peritumoral infiltrating cell densities and $\mathrm{MVD}^{1}$

\begin{tabular}{lcccccc}
\hline \multirow{2}{*}{ Tumor category } & No. of cases & \multicolumn{5}{c}{ Cell type marker } \\
\cline { 3 - 7 } & & CD3 & CD8 & CD20 & CD68 & CD1a \\
\hline All tumors & 52 & $0.2950^{\mathrm{a}}$ & -0.0900 & 0.1305 & 0.1570 & 0.1910 \\
Thickness (mm) & & & & & & -0.0769 \\
$\quad 1.01-2.0$ & 23 & -0.1209 & $-0.6573^{\mathrm{c}}$ & -0.0559 & 0.1748 & $0.5791^{\mathrm{c}}$ \\
$2.01-4.0$ & 16 & 0.0451 & -0.0110 & 0.0215 & -0.3104 & 0.3712 \\
$>4.0$ & & $0.7643^{\mathrm{d}}$ & $0.7758^{\mathrm{d}}$ & 0.3500 & $0.5794^{\mathrm{b}}$ & -0.2021 \\
Metastasis & 19 & 0.0857 & -0.2181 & -0.3024 & 0.0237 & 0.3713 \\
$\quad$ Nonmetastatic & 8 & $0.7143^{\mathrm{a}}$ & 0.0952 & 0.0000 & 0.4524 & $0.4344^{\mathrm{a}}$ \\
$\quad$ LN metastatic & 25 & $0.5209^{\mathrm{c}}$ & $0.5011^{\mathrm{b}}$ & $0.4213^{\mathrm{a}}$ & 0.1350 & \\
$\quad$ Visceral metastatic & 25 & &
\end{tabular}

${ }^{1}$ Spearman's rank correlation coefficients; ${ }^{a} \mathrm{p}<0.05,{ }^{\mathrm{b}} \mathrm{p}<0.02,{ }^{\mathrm{c}} \mathrm{p}<0.01,{ }^{\mathrm{d}} \mathrm{p}<0.001$

a microvessel. We selected three vascular hot spots both intratumorally and peritumorally for counting $\mathrm{CD} 34^{+}$ microvessels. The number of $\mathrm{CD}^{+}, \mathrm{CD}^{+}$or $\mathrm{CD} 20^{+}$lymphocytes, $\mathrm{CD} 1 \mathrm{a}^{+}$dendritic cells and $\mathrm{CD} 68^{+}$macrophages was registered separately in intratumoral (infiltrating melanoma cell nests) and peritumoral areas (distributed in the infiltrate along the margin and the base of melanomas) at five randomly selected sites, and the density of positive cells $/ \mathrm{mm}^{2}$ was calculated (Fig. $1 c-f$ ).

\section{Statistical analysis}

Statistical comparison between cell densities in different tumor groups was made by using the Mann-Whitney U test and Kruskal-Wallis test. The correlation between the density of $\mathrm{CD}^{+}, \mathrm{CD}^{+}, \mathrm{CD} 20^{+}, \mathrm{CD} 8^{+}, \mathrm{CD} 1 \mathrm{a}^{+}$infiltrating cells and MVD was evaluated by using Spearman's rank correlation test. All statistics were calculated using the BMDP Statistical Software Pack.

\section{Results}

Correlation between microvessel density and tumor infiltrates

We have analyzed the correlations of infiltrating cell densities with MVD in samples grouped according to tumor thickness and metastasis formation. Intratumoral infiltration did not show significant association with MVD in any of these groups for any of the cell types studied. In the case of peritumoral cell densities, when analyzing the whole patient population, the only statistically significant correlation was found between MVD and the density of $\mathrm{CD}^{+} \mathrm{T}$ cells $(\mathrm{p}<0.05)$ (Table 2). This association was stronger in the highest thickness category $(>4.0 \mathrm{~mm})$, as well as in the group of visceral metastatic tumors $(\mathrm{p}<0.001$ and $\mathrm{p}<0.01$, respectively). In these subgroups of patients similar phenomenon was observed in the case of $\mathrm{CD}^{+}$cells (Table 2).
In melanomas thicker than $4.0 \mathrm{~mm}$ MVD positively correlated with macrophage density as well, while weak associations were found in the case of B-cell and DC infiltration in visceral metastatic tumors. In contrast, no correlations could be seen for thinner (1.01-2.0 mm) or nonmetastatic melanomas in the case of the majority of markers (Table 2).

Analysis of the correlations found in the visceral metastatic group after subdivision of the cases according to tumor thickness indicated that all these associations were present only in the subgroup of melanomas $>4.0 \mathrm{~mm}$ $(n=9)$, while no significant correlations were seen in the case of tumors $\leq 4.0 \mathrm{~mm}(\mathrm{n}=16)$.

Comparison of microvessel densities in the different tumor categories

Peritumoral microvessel density was found to be more than twice as high as intratumoral one (Table 3), confirming our earlier findings. ${ }^{18}$ Peritumoral MVD demonstrated a tendency to increase parallel with tumor thickness, while intratumoral MVD in 2.01-4.0 mm melanomas showed a trend to exceed that of the other two thickness categories, however, these differences were not statistically significant. We could not detect significant differences in MVD when comparing melanomas according to localization, histological type (SSM vs. NM), metastasis formation, or the presence of ulceration in the primary tumors. However, in the male patient group intratumoral MVD was significantly higher than in females $(\mathrm{p}=0.0303)$ (Table 3).

\section{Variation of T-cell and macrophage infiltration with clinical parameters}

In the followings we examined the possible associations of patient and tumor parameters with the density of $\mathrm{T}$ cells and macrophages, the two predominating cell types in 
melanoma infiltrate which showed correlations with vascularization.

Intratumoral and peritumoral density of $\mathrm{CD}^{+} 8^{+}$ macrophages was higher in melanomas thicker than 2.0 $\mathrm{mm}$, compared to thinner ones $(\mathrm{p}=0.0259$ and $\mathrm{p}=0.0520$, respectively) (Table 4 ). There was no significant difference in macrophage infiltration between the subgroups of 2-4 $\mathrm{mm}$ and $>4 \mathrm{~mm}$ thickness categories. Similarly to MVD, the density of intratumoral macrophage infiltration was lower in females than in males $(\mathrm{p}=0.0527)$, while no difference was observed in peritumoral cell density. Localization, histological type, ulceration and clinical outcome did not significantly influence macrophage infiltration.

Distant organ metastasis showed a trend for association with lower intratumoral and peritumoral density of $\mathrm{CD}^{+} \mathrm{T}$ lymphocytes, compared to the non-metastatic group (borderline significance) (Table 5). Similar association was observed in the case of peritumoral $\mathrm{CD}^{+} \mathrm{T}$ cells (not shown). Intratumoral and peritumoral T-cell infiltration was not affected by tumor thickness, localization, histological type, and patients' sex, while ulcerated tumors showed a trend to be associated by lower intratumoral density of $\mathrm{CD}^{+} \mathrm{T}$ lymphocytes and lower peritumoral density of $\mathrm{CD} 8^{+} \mathrm{T}$ cells (Table 5 and not shown).

\section{Discussion}

According to our present observations, intra- and peritumoral MVD did not significantly change with tumor thickness and metastatic pattern. Localization, ulceration and histological type (SSM vs. NM) of melanomas did not influence tumor vascularity either. These observations are partly in harmony with our previous data suggesting that peritumoral microvessel density judged by the common hot spot technique is not related to clinicopathological parameters in melanoma. ${ }^{18}$ On the other hand, our previous study reported a significant association between the central intratumoral vessel density and visceral metastasis of melanoma. ${ }^{18}$ In the present study we did not discriminate central microvessels since we have applied the hot spot technique to analyze the areas of highest vessel density, where we primarily expected an association of MVD with infiltrating cells.

Table 3. Variation of MVD with patient and tumor characteristics

\begin{tabular}{|c|c|c|c|c|c|}
\hline \multirow{3}{*}{ Patient group } & \multirow{3}{*}{ Patient no. } & \multicolumn{4}{|c|}{$\mathrm{CD} 4^{+}$microvessels } \\
\hline & & \multicolumn{2}{|c|}{ Intratumoral } & \multicolumn{2}{|c|}{ Peritumoral } \\
\hline & & Mean $\pm S D$ & $p$ & Mean $\pm S D$ & $p$ \\
\hline \multicolumn{6}{|l|}{ Sex } \\
\hline Male & 24 & $97.6 \pm 33.6$ & & $202.0 \pm 78.8$ & \\
\hline Female & 28 & $76.8 \pm 34.4$ & $0.0303^{1}$ & $216.0 \pm 106.0$ & $0.8114^{1}$ \\
\hline \multicolumn{6}{|l|}{ Localization } \\
\hline Extremities & 21 & $84.4 \pm 31.6$ & & $207.6 \pm 88.0$ & \\
\hline Trunk or head & 31 & $87.6 \pm 38.0$ & $0.8302^{1}$ & $210.4 \pm 98.8$ & $0.9331^{1}$ \\
\hline \multicolumn{6}{|l|}{ Type } \\
\hline SSM & 30 & $79.6 \pm 30.0$ & & $201.2 \pm 86.4$ & \\
\hline $\mathrm{NM}$ & 19 & $94.4 \pm 41.2$ & $0.2032^{1}$ & $221.6 \pm 112.0$ & $0.7195^{1}$ \\
\hline \multicolumn{6}{|l|}{ Thickness (mm) } \\
\hline $1.01-2.0$ & 13 & $75.6 \pm 39.6$ & & $174.0 \pm 83.2$ & \\
\hline $2.01-4.0$ & 23 & $97.2 \pm 36.0$ & & $216.0 \pm 98.8$ & \\
\hline$>4.0$ & 16 & $79.6 \pm 27.6$ & $0.1593^{2}$ & $228.8 \pm 92.0$ & $0.2437^{2}$ \\
\hline \multicolumn{6}{|l|}{ Metastasis } \\
\hline Nonmetastatic & 19 & $89.6 \pm 44.0$ & & $220.3 \pm 118.4$ & \\
\hline LN metastatic & 8 & $77.2 \pm 26.0$ & & $208.0 \pm 88.4$ & \\
\hline Visceral metastatic & 25 & $86.8 \pm 31.2$ & $0.5948^{2}$ & $201.6 \pm 75.2$ & $0.9683^{2}$ \\
\hline \multicolumn{6}{|l|}{ Ulceration } \\
\hline Present & 35 & $90.8 \pm 36.8$ & & $216.8 \pm 96.8$ & \\
\hline Absent & 17 & $77.2 \pm 30.8$ & $0.2013^{1}$ & $194.4 \pm 87.6$ & $0.4182^{1}$ \\
\hline \multicolumn{6}{|l|}{ 5-year survival } \\
\hline Yes & 28 & $86.4 \pm 38.8$ & & $215.2 \pm 107.2$ & \\
\hline No & 24 & $86.4 \pm 32.0$ & $0.8688^{1}$ & $202.8 \pm 76.8$ & $0.8472^{1}$ \\
\hline
\end{tabular}

Data are expressed as number of microvessels $/ \mathrm{mm}^{2}$. ALM (2) and LM (1) cases are not shown. SSM: superficial spreading melanoma; NM: nodular melanoma; ALM: acral lentiginous melanoma; LMM: lentigo maligna melanoma. p: significance of difference by ${ }^{1}$ Mann-Whitney U-test or ${ }^{2}$ Kruskal-Wallis test 
Table 4. Variation of macrophage density with patient and tumor characteristics

\begin{tabular}{|c|c|c|c|c|c|}
\hline \multirow{3}{*}{ Patient group } & \multirow{3}{*}{ Patient no. } & \multicolumn{4}{|c|}{$\mathrm{CD} 68^{+}$macrophages } \\
\hline & & \multicolumn{2}{|c|}{ Intratumoral } & \multicolumn{2}{|c|}{ Peritumoral } \\
\hline & & Mean $\pm S D$ & $p$ & Mean $\pm S D$ & $p$ \\
\hline \multicolumn{6}{|l|}{ Sex } \\
\hline Male & 24 & $209.6 \pm 156.4$ & & $403.2 \pm 309.6$ & \\
\hline Female & 27 & $132.0 \pm 136.0$ & $0.0527^{1}$ & $447.2 \pm 230.4$ & $0.3854^{1}$ \\
\hline \multicolumn{6}{|l|}{ Localization } \\
\hline Extremities & 20 & $169.2 \pm 149.6$ & & $416.4 \pm 281.2$ & \\
\hline Trunk or head & 31 & $166.4 \pm 152.0$ & $0.8663^{1}$ & $433.2 \pm 264.8$ & $0.8319^{1}$ \\
\hline \multicolumn{6}{|l|}{ Type } \\
\hline SSM & 29 & $154.8 \pm 152.4$ & & $388.0 \pm 256.4$ & \\
\hline NM & 19 & $198.4 \pm 153.2$ & $0.2688^{1}$ & $497.6 \pm 290.0$ & $0.2420^{1}$ \\
\hline \multicolumn{6}{|l|}{ Thickness (mm) } \\
\hline $1.01-2.0$ & 12 & $88.0 \pm 138.4$ & & $258.8 \pm 196.0$ & \\
\hline $2.01-4.0$ & 23 & $188.0 \pm 136.4$ & & $486.0 \pm 286.0$ & \\
\hline$>4.0$ & 16 & $199.6 \pm 161.6$ & $0.0259^{2}$ & $467.6 \pm 250.8$ & $0.0520^{2}$ \\
\hline \multicolumn{6}{|l|}{ Metastasis } \\
\hline Nonmetastatic & 18 & $188.0 \pm 164.0$ & & $472.0 \pm 267.2$ & \\
\hline LN metastatic & 8 & $72.8 \pm 48.8$ & & $419.6 \pm 242.8$ & \\
\hline Visceral metastatic & 25 & $184.0 \pm 152.8$ & $0.1620^{2}$ & $396.4 \pm 283.2$ & $0.5089^{2}$ \\
\hline \multicolumn{6}{|l|}{ Ulceration } \\
\hline Present & 35 & $162.0 \pm 147.6$ & & $438.0 \pm 296.4$ & \\
\hline Absent & 16 & $179.6 \pm 157.6$ & $0.7314^{1}$ & $401.2 \pm 201.2$ & $0.8710^{1}$ \\
\hline \multicolumn{6}{|l|}{ 5-year survival } \\
\hline Yes & 27 & $146.8 \pm 148.0$ & & $439.2 \pm 265.2$ & \\
\hline No & 24 & $192.0 \pm 151.2$ & $0.1921^{1}$ & $412.4 \pm 277.6$ & $0.5334^{1}$ \\
\hline
\end{tabular}

Data are expressed as number of macrophages $/ \mathrm{mm}^{2}$. ALM (2) and LMM (1) cases are not shown. SSM: superficial spreading melanoma; NM: nodular melanoma; ALM: acral lentiginous melanoma; LMM: lentigo maligna melanoma. p: significance of difference by ${ }^{1}$ Mann-Whitney U-test or ${ }^{2}$ Kruskal-Wallis test

The relationship between angiogenesis and macrophage infiltration in cutaneous melanoma is not clear yet. Some authors described a correlation between macrophage number and microvessel count, ${ }^{48,61}$ which was, however, not confirmed by other studies. ${ }^{62}$ We could not find significant association between the intratumoral and peritumoral density of macrophages and $\mathrm{CD} 34^{+}$microvessels, the correlation being significant only when we examined peritumoral microvessels in the highest thickness category. Concomitantly, intratumoral and peritumoral macrophage densities were significantly higher in melanomas thicker than $2 \mathrm{~mm}$, compared to thinner ones. Similarly, more intense macrophage infiltration in thicker melanomas has been reported by other observers. ${ }^{7,62}$ Our results support the role of macrophages in vascularization of high-risk melanomas. According to Leek et al, monocytes are continually recruited into tumors, differentiate into tumorassociated macrophages, accumulate in hypoxic areas, and may induce angiogenesis through secretion of angiogenic cytokines including TNF- $\alpha$, IL- $1 \alpha$ and VEGF. ${ }^{36,37}$ In the case of melanoma their role is more complex, since they may increase angiogenesis peritumorally, and, on the other hand, promote the survival of the incorporated vessels intratumorally.

T lymphocyte infiltration is generally regarded as evidence of an ongoing immune response against the developing neoplasm, however, a possible role of $\mathrm{T}$ cells in tumor vascularization has also been suggested. ${ }^{21}$ We found that peritumoral microvessel densities correlated significantly with the number of peritumoral $\mathrm{CD}^{+}$cells. The correlation was more pronounced in melanomas thicker than $4.0 \mathrm{~mm}$, and also in those with distant metastases, in the latter case probably mainly as a consequence of the higher prevalence of thick tumors in the visceral metastatic group. The association of MVD with T-cell density suggests that, although peritumoral vascular density did not have a significant role in directly modulating melanoma progression, it could influence the intensity of peritumoral T-cell infiltration, therefore, a higher MVD might even have a positive role in contributing to an increased local T-cell density. Alternatively, associations between the intensity of vascularization and $\mathrm{T}$ lymphocyte infiltration may be a result 
of increased concentration of angiogenic factors in T-cellrich peritumoral areas.

We observed higher intratumoral microvessel density in males than in females, which was probably not due to differences in other tumor characteristics like thickness or localization, since they did not influence vascularization significantly, and there was no significant difference in the gender distribution according to these parameters. This finding indicates the possible involvement of sex hormones in the vascularization of melanoma. Steroid hormones have been described to have an effect on angiogenesis. Endothelial cells express the classic estrogen receptor, ${ }^{30}$ and estradiol was demonstrated to inhibit apoptosis and induce proliferation and migration of these cells. ${ }^{38,58}$ Moreover, estrogen has also been shown to enhance angiogenesis via platelet factor-mediated activation of NF- $\kappa \mathrm{B}$, leading to the production of IL- 8 , bFGF and VEGF. ${ }^{57}$ On the other hand, the endogenous estrogen metabolite, 2-methoxyestradiol has been reported to inhibit endothelial cell proliferation, as well as angiogenesis, tumor growth and metastasis in several tumor types, including melanoma. ${ }^{16,20,52}$ Medroxyprogesterone also inhibited growth and vascularization of melanoma in the rabbit cornea. ${ }^{23}$ Androgens may stimulate angiogenesis through regulation of VEGF levels via the activation of $\mathrm{HIF},{ }^{39}$ or through suppressing the secretion of thrombospondin-1, an angiogenesis inhibitor. ${ }^{11}$

Similarly to MVD, intratumoral macrophage density was also higher in male patients compared to females in our study. This finding might be explained in part by gender-specific differences in the recruitment of macrophages in the tumor. This hypothesis is supported by the demonstration of the inhibitory effect of estrogen on the expression of monocyte chemotactic protein-1 (MCP-1) and on macrophage infiltration in various tissues. ${ }^{1,56}$

According to our results, associations between MVD and infiltrating cell densities were observed only peritumorally, and not intratumorally. This difference might partly be explained by the altered endothelial phenotype in these locations. Loss of several endothelial cell adhesion molecules from tumor-associated microvessels has been described. ${ }^{46}$ We have previously reported that intratumoral

Table 5. Variation of T-cell density with patient and tumor characteristics

\begin{tabular}{|c|c|c|c|c|c|}
\hline \multirow{3}{*}{ Patient group } & \multirow{3}{*}{ Patient no. } & \multicolumn{4}{|c|}{$\mathrm{CD}^{+} \mathrm{T}$ cells } \\
\hline & & \multicolumn{2}{|c|}{ Intratumoral } & \multicolumn{2}{|c|}{ Peritumoral } \\
\hline & & Mean $\pm S D$ & $p$ & Mean $\pm S D$ & $p$ \\
\hline \multicolumn{6}{|l|}{ Sex } \\
\hline Male & 22 & $110.4 \pm 122.4$ & & $780.8 \pm 587.6$ & \\
\hline Female & 26 & $73.6 \pm 78.8$ & $0.6929^{1}$ & $797.2 \pm 536.0$ & $0.7096^{1}$ \\
\hline \multicolumn{6}{|l|}{ Localization } \\
\hline Extremities & 18 & $78.4 \pm 82.4$ & & $657.2 \pm 425.6$ & \\
\hline Trunk or head & 30 & $97.6 \pm 112.4$ & $0.5928^{1}$ & $869.2 \pm 612.0$ & $0.3067^{1}$ \\
\hline \multicolumn{6}{|l|}{ Type } \\
\hline SSM & 29 & $78.8 \pm 86.8$ & & $745.6 \pm 583.2$ & \\
\hline NM & 16 & $110.8 \pm 119.2$ & $0.6596^{1}$ & $898.8 \pm 541.2$ & $0.2860^{1}$ \\
\hline \multicolumn{6}{|l|}{ Thickness (mm) } \\
\hline $1.01-2.0$ & 13 & $96.0 \pm 100.4$ & & $766.8 \pm 701.6$ & \\
\hline $2.01-4.0$ & 20 & $82.8 \pm 115.2$ & & $795.2 \pm 512.0$ & \\
\hline$>4.0$ & 15 & $96.0 \pm 88.8$ & $0.5017^{2}$ & $802.8 \pm 503.6$ & $0.8254^{2}$ \\
\hline \multicolumn{6}{|l|}{ Metastasis } \\
\hline Nonmetastatic & 18 & $112.0 \pm 108.8$ & & $1000.0 \pm 642.0$ & \\
\hline LN metastatic & 7 & $99.2 \pm 101.2$ & $0.9276^{3}$ & $748.0 \pm 595.2$ & $0.3968^{3}$ \\
\hline Visceral metastatic & 23 & $70.8 \pm 96.8$ & $0.0903^{3}$ & $638.0 \pm 424.8$ & $0.0659^{3}$ \\
\hline \multicolumn{6}{|l|}{ Ulceration } \\
\hline Present & 32 & $76.4 \pm 93.2$ & & $732.0 \pm 478.4$ & \\
\hline Absent & 16 & $118.0 \pm 114.8$ & $0.0972^{1}$ & $906.0 \pm 684.0$ & $0.3937^{1}$ \\
\hline \multicolumn{6}{|l|}{ 5-year survival } \\
\hline Yes & 26 & $104.4 \pm 104.8$ & & $920.4 \pm 616.8$ & \\
\hline No & 22 & $74.0 \pm 97.6$ & $0.1515^{1}$ & $635.6 \pm 434.8$ & $0.1111^{1}$ \\
\hline
\end{tabular}

Data are expressed as number of $\mathrm{CD}^{+} \mathrm{T}$ cells $/ \mathrm{mm}^{2}$. ALM (2) and LMM (1) cases are not shown. SSM: superficial spreading melanoma; NM: nodular melanoma; ALM: acral lentiginous melanoma; LMM: lentigo maligna melanoma. p: significance of difference by ${ }^{1}$ Mann-Whitney U-test or ${ }^{2}$ Kruskal-Wallis test; ${ }^{3}$ Mann-Whitney U-test, compared to the nonmetastatic group 
(coopted) microvessels in skin melanoma gradually loose the expression of vascular adhesion protein-1 (VAP-1) from endothelial cells, ${ }^{19}$ a molecule that is critical in lymphocyte-endothelial cell interactions in the skin. ${ }^{2}$ It is tempting to speculate that such changes in intratumoral microvessels can contribute to the defect of immune reaction to melanoma. Supporting this suggestion, in our previous study the loss of VAP-1 expression was associated with poor prognosis of the disease. ${ }^{19}$ As an alternative explanation, the absence of correlation between intratumoral cell densities and MVD could derive from differences in the mechanisms of vascular development between intratumoral and peritumoral areas in melanoma. According to our previous findings, ${ }^{18}$ endothelial cell proliferation within the tumor participates in vessel dilatation instead of formation of new vessels, the latter being confined mainly to peritumoral areas. As a possible consequence, angiogenic compounds potentially produced by infiltrating cells would only affect peritumoral vascular development in this tumor type.

Our observations that peritumoral microvessel density was found to be positively correlated with the density of various immune cells ( $\mathrm{T}$ and B lymphocytes, macrophages and dendritic cells) in thick and in visceral metastatic tumors suggest that a functioning "immune-vascular" network may be associated with tumor progression. This is further supported by our observation that in the case of thin tumors $(1-2 \mathrm{~mm})$, the prognosis of which being far better as compared to thick ones, no correlation was detected between MVD and most infiltrating cell types. These findings might also help us to better interpret the higher vascularization of regressive melanomas, ${ }^{6}$ which are generally infiltrated by immune cells, the prognostic significance of which is controversial. ${ }^{51,54}$ Since the net outcome of the enrichment in tumor-infiltrating host cells cannot be easily predicted without defining their individual role in the antitumor defense, further clinicopathological studies are needed on human skin melanoma patients.

\section{Acknowledgements}

We thank K. Derecskei, V. Piurkó, V. Gregor and I. Sinkáné for their excellent technical assistance. The study was supported by Hungarian Ministry of Health grant ETT 425/2006, grants GVOP3.11.-2004-05-0090.3.0 and NKFP1a-0024-05.

\section{References}

1. Arici A, Senturk LM, Seli E, Bahtiyar MO, Kim G: Regulation of monocyte chemotactic protein-1 expression in human endometrial stromal cells by estrogen and progesterone. Biol Reprod 61: 85-90, 1999

2. Arvilommi AM, Salmi M, Kalimo K, Jalkanen S: Lymphocyte binding to vascular endothelium in inflamed skin revisited: a central role for vascular adhesion protein-1 (VAP-1). Eur J Immunol 26: 825-833, 1996
3. Ausprunk DH, Folkman J: Migration and proliferation of endothelial cells in performed and newly formed blood vessels during tumor angiogenesis. Microvasc Res 14: 53-65, 1977

4. Balch CM, Buzaid AC, Soong S-J, Atkins MB, Cascinelli N, Coit DG, Fleming ID, Gershenwald JE, Houghton A Jr, Kirkwood JM, McMasters KM, Mihm MF, Morton DL, Reintgen DS, Ross MI, Sober A, Thompson JA, Thompson JF: Final version of the American Joint Committee on Cancer staging system for cutaneous melanoma. J Clin Oncol 19: 3635-3648, 2001

5. Barnhill RL, Fine JA, Roush GC, Berwick $M$ : Predicting fiveyear outcome for patients with cutaneous melanoma in a population-based study. Cancer 78: 427-432, 1996

6. Barnhill RL, Levy MA: Regressing thin cutaneous malignant melanomas $(<$ or $=1.0 \mathrm{~mm})$ are associated with angiogenesis. Am J Pathol 143: 99-104, 1993

7. Bröcker EB, Zwadlo G, Holzmann B, Macher E, Sorg C: Inflammatory cell infiltrates in human malignant melanoma at different stages of tumor progression. Int. J. Cancer 41: 562-567, 1988

8. Busam KJ, Berwick M, Blessing K, Fandrey K, Kang S, Karaoli T, Fine J, Cochran AJ, White WL, Rivers J: Tumor vascularity is not a prognostic factor for malignant melanoma of the skin. Am J Pathol 147: 1049-1056, 1995

9. Clark WH Jr, Elder DE, Guerry D 4th, Braitman LE, Trock BJ, Schultz D, Synnestvedt M, Halpern AC: Model predicting survival in stage I melanoma based on tumor progression. J Natl Cancer Inst 81: 1893-1904, 1989

10. Clemente CG, Mihm MC Jr, Bufalino R, Zurrida S, Collini P, Cascinelli $N$ : Prognostic value of tumor infiltrating lymphocytes in the vertical growth phase of primary cutaneous melanoma. Cancer 77: 1303-1310, 1996

11. Colombel M, Filleur S, Fournier P, Merle C, Guglielmi J, Courtin A, Degeorges A, Serre CM, Bouvier R, Clezardin P, Cabon F: Androgens repress the expression of the angiogenesis inhibitor thrombospondin-1 in normal and neoplastic prostate. Cancer Res 65: 300-308, 2005

12. Coukos G, Benencia F, Buckanovich RJ, Conejo-Garcia JR: The role of dendritic cell precursors in tumour vasculogenesis. Br J Cancer 92: 1182-1187, 2005

13. Curiel TJ, Cheng P, Mottram P, Alvarez X, Moons L, EvdemonHogan M, Wei S, Zou L, Kryczek I, Hoyle G, Lackner A, Carmeliet $P$, Zou $W$ : Dendritic cell subsets differentially regulate angiogenesis in human ovarian cancer. Cancer Res 64: 5535-5538, 2004

14. Davidson B, Goldberg I, Gotlieb WH, Lerner-Geva L, BenBaruch G, Agulansky L, Novikov I, Kopolovic J: Macrophage infiltration and angiogenesis in cervical squamous cell carcinoma - clinicopathologic correlation. Acta Obstet Gynecol Scand 78: 240-244, 1999

15. Depasquale I, Thompson WD: Microvessel density for melanoma prognosis. Histopathology 47: 186-194, 2005

16. Dobos J, Tímár J, Bocsi J, Burián Z, Nagy K, Barna G, Peták I, Ladányi $A$ : In vitro and in vivo antitumor effect of 2-methoxyestradiol on human melanoma. Int J Cancer 112: 771-776, 2004

17. Döme J, Hendrix MJC, Paku S, Tóvári J, Tímár J: Alternative vascularization mechanisms in cancer: pathology and therapeutic implications. Am J Pathol, 170: 1-15, 2007

18. Döme B, Paku S, Somlai B, Tímár J: Vascularization of cutaneous melanoma involves vessel co-option and has clinical significance. J Pathol 97: 355-362, 2002

19. Forster-Horváth C, Döme B, Paku S, Ladányi A, Somlai B, Jalkanen $S$, Tímár $J$ : Loss of vascular adhesion protein-1 expression in intratumoral microvessels of human skin melanoma. Melanoma Res 14: 135-140, 2004 
20. Fotsis T, Zhang Y, Pepper MS, Adlercreutz H, Montesano $R$, Nawroth PP, Schweigerer L: The endogenous oestrogen metabolite 2-methoxyoestradiol inhibits angiogenesis and suppresses tumour growth. Nature 368: 237-239, 1994

21. Freeman MR, Schneck FX, Gagnon ML, Corless C, Soker S, Niknejad K, Peoples GE, Klagsbrun M: Peripheral blood T lymphocytes and lymphocytes infiltrating human cancers express vascular endothelial growth factor: a potential role for $\mathrm{T}$ cells in angiogenesis. Cancer Res 55: 4140-4145, 1995

22. Gabrilovich DI, Chen HL, Girgis KR, Cunningham HT, Meny GM, Nadaf S, Kavanaugh D, Carbone DP: Production of vascular endothelial growth factor by human tumors inhibits the functional maturation of dendritic cells. Nat Med 2: 1096-1103, 1996

23. Gross J, Azizkhan RG, Biswas C, Bruns RR, Hsieh DS, Folkman $J$ : Inhibition of tumor growth, vascularization, and collagenolysis in the rabbit cornea by medroxyprogesterone. Proc Natl Acad Sci U S A 78: 1176-1180, 1981

24. Hanada T, Nakagawa M, Emoto A, Nomura T, Nasu N, Nomuray: Prognostic value of tumor-associated macrophage count in human bladder cancer. Int J Urol 7: 263-269, 2000

25. Ilmonen S, Kariniemi AL, Vlaykova T, Muhonen T, Pyrhonen S, Asko-Seljavaara $S$ : Prognostic value of tumour vascularity in primary melanoma. Melanoma Res 9: 273-278, 1999

26. Inoshima N, Nakanishi Y, Minami T, Izumi M, Takayama $K$, Yoshino I, Hara N: The influence of dendritic cell infiltration and vascular endothelial growth factor expression on the prognosis of non-small cell lung cancer. Clin Cancer Res 8: 34803486, 2002

27. Ishigami S, Aikou T, Natsugoe S, Hokita S, Iwashige H, Tokushige $M$, Sonoda S: Prognostic value of HLA-DR expression and dendritic cell infiltration in gastric cancer. Oncology 55: 65-69, 1998

28. Ishigami S, Natsugoe S, Matsumoto M, Okumura H, Sakita H, Nakashima S, Takao S, Aikou T: Clinical implications of intratumoral dendritic cell infiltration in esophageal squamous cell carcinoma. Oncol Rep 10: 1237-1240, 2003

29. Kashani-Sabet M, Sagebiel RW, Ferreira CM, Nosrati M, Miller $J R 3^{r d}$ : Tumor vascularity in the prognostic assessment of primary cutaneous melanoma. J Clin Oncol 20: 1826-1831, 2002

30. Kim-Schulze S, McGowan KA, Hubchak SC, Cid MC, Martin $M B$, Kleinman HK, Greene GL, Schnaper HW: Expression of an estrogen receptor by human coronary artery and umbilical vein endothelial cells. Circulation 94: 1402-1407, 1996

31. Koch AE, Polverini PJ, Kunkel SL, Harlow LA, DiPietro LA, Elner VM: Interleukin-8 as a macrophage-derived mediator of angiogenesis. Science 258: 1798-1801, 1992

32. Kono K, Salazar-Onfray F, Petersson M, Hansson J, Masucci $G$, Wasserman $K$, Nakazawa $T$, Anderson $P$, Kiessling $R$ : Hydrogen peroxide secreted by tumor-derived macrophages down-modulates signal-transducing zeta molecules and inhibits tumor-specific T cell- and natural killer cell-mediated cytotoxicity. Eur J Immunol 26:1308-1313, 1996

33. Lackner C, Jukic Z, Tsybrovskyy O, Jatzko G, Wette V, Hoefler $G$, Klimpfinger $M$, Denk $H$, Zatloukal K: Prognostic relevance of tumour-associated macrophages and von Willebrand factorpositive microvessels in colorectal cancer. Virchows Arch 445: 160-167, 2004

34. Ladányi A, Kiss J, Somlai B, Gilde K, Fejôs Z, Mohos A, Gaudi I, Tímár $J$ : Density of DC-LAMP ${ }^{+}$mature dendritic cells in combination with activated $\mathrm{T}$ lymphocytes infiltrating primary cutaneous melanoma is a strong independent prognostic factor. Cancer Immunol Immunother Epub DOI 10.1007/s00262-0070286-3, 2007
35. Ladányi A, Somlai B, Gilde K, Fejös Z, Gaudi I, Tímár J: T-cell activation marker expression on tumor-infiltrating lymphocytes as prognostic factor in cutaneous malignant melanoma. Clin Cancer Res 10:521-530, 2004

36. Leek RD, Harris AL, Lewis CE: Cytokine networks in solid human tumors: regulation of angiogenesis. J Leukoc Biol 56: 423-435, 1994

37. Leek RD, Lewis CE, Whitehouse R, Greenall M, Clarke J, Harris $A L$ : Association of macrophage infiltration with angiogenesis and prognosis in invasive breast carcinoma. Cancer Res 56: 4625-4629, 1996

38. Losordo DW, Isner JM: Estrogen and angiogenesis: A review. Arterioscler Thromb Vasc Biol 21: 6-12, 2001

39. Mabjeesh NJ, Willard MT, Frederickson CE, Zhong H, Simons $J W$ : Androgens stimulate hypoxia-inducible factor 1 activation via autocrine loop of tyrosine kinase receptor/phosphatidylinositol 3'-kinase/protein kinase B in prostate cancer cells. Clin Cancer Res 9: 2416-2425, 2003

40. Madtes DK, Raines EW, Sakariassen KS, Assoian RK, Sporn $M B$, Bell GI: Induction of transforming growth factor-alpha in human alveolar macrophages. Cell 53: 285-293, 1988

41. Makitie T, Summanen P, Tarkkanen A, Kivela T: Tumor-infiltrating macrophages (CD68-positive cells) and prognosis in malignant uveal melanoma. Invest Ophthalmol Vis Sci 42: 1414-1421, 2001

42. Mantovani A, Bottazzi B, Colotta F, Sozzani S, Ruco L: The origin and function of tumor-associated macrophages. Immunol Today 13: 265-270, 1992

43. Marcoval J, Moreno A, Graells J, Vidal A, Escriba JM, GarciaRamirez M, Fabra A: Angiogenesis and malignant melanoma. Angiogenesis is related to the development of vertical (tumorigenic) growth phase. J Cutan Pathol 24: 212-218, 1997

44. Marincola FM, Jaffee EM, Hicklin DJ, Ferrone S: Escape of human solid tumors from T-cell recognition: molecular mechanisms and functional significance. Adv Immunol 74: 181273, 2000

45. McBride $W H$ : Phenotype and functions of intratumoral macrophages. Biochim Biophys Acta 865: 27-41, 1986

46. McDonald DM, Foss AJE: Endothelial cells of tumor vessels: abnormal but not absent. Cancer Metastasis Rev 19: 109-120, 2002

47. Miescher S, Whiteside TL, Carrel S, von Fliedner V: Functional properties of tumor-infiltrating and blood lymphocytes in patients with solid tumors: effects of tumor cells and their supernatants on proliferative responses of lymphocytes. J Immunol 136: 1899-1907, 1986

48. Ono M, Torisu H, Fukushi J-I, Nishie A, Kuwano M: Biological implications of macrophage infiltration in human tumor angiogenesis. Cancer Chemother Pharmacol 43: 69-71, 1999

49. Peng SH, Deng H, Yang JF, Xie PP, Li C, Li, Feng DY: Significance and relationship between infiltrating inflammatory cell and tumor angiogenesis in hepatocellular carcinoma tissues. World J Gastroenterol 11: 6521-6524, 2005

50. Piras F, Colombari R, Minerba L, Murtas D, Floris C, Maxia $C$, Corbu A, Perra MT, Sirigu P: The predictive value of CD8, CD4, CD68, and human leukocyte antigen-D-related cells in the prognosis of cutaneous malignant melanoma with vertical growth phase. Cancer 104: 1246-1254, 2005

51. Prehn RT: The paradoxical association of regression with a poor prognosis in melanoma contrasted with a good prognosis in keratoacanthoma. Cancer Res 56: 937-940, 1996

52. Pribluda VS, Gubish ER Jr, Lavallee TM, Treston A, Swartz GM, Green SJ: 2-Methoxyestradiol: an endogenous antiangiogenic and antiproliferative drug candidate. Cancer Metastasis Rev 19: 173-179, 2000 
53. Qin Z, Schwartzkopff J, Pradera F, Kammertoens T, Seliger B, Pircher H, Blankenstein T: A critical requirement of interferon gamma-mediated angiostasis for tumor rejection by CD8+ T cells. Cancer Res 63: 4095-4100, 2003

54. Ronan SG, Eng AM, Briele HA, Shioura NN, Das Gupta TK: Thin malignant melanomas with regression and metastases. Arch Dermatol 123: 1326-1330, 1987

55. Saito H, Tsujitani S, Ikeguchi M, Maeta M, Kaibara N: Relationship between the expression of vascular endothelial growth factor and the density of dendritic cells in gastric adenocarcinoma tissue. Br J Cancer 78: 1573-1577, 1998

56. Seli E, Pehlivan T, Selam B, Garcia-Velasco JA, Arici A: Estradiol down-regulates MCP-1 expression in human coronary artery endothelial cells. Fertil Steril 77: 542-547, 2002

57. Seo KH, Lee HS, Jung B, Ko HM, Choi JH, Park SJ, Choi IH, Lee HK, Im SY: Estrogen enhances angiogenesis through a pathway involving platelet-activating factor-mediated nuclear factor-kappaB activation. Cancer Res 64: 6482-6488, 2004

58. Spyridopoulos I, Sullivan AB, Kearney M, Isner JM, Losordo $D W:$ Estrogen-receptor-mediated inhibition of human endothelial cell apoptosis. Estradiol as a survival factor. Circulation 95: 1505-1514, 1997
59. Straume $O$, Salvesen HB, Akslen LA: Angiogenesis is prognostically important in vertical growth phase melanomas. Int $\mathrm{J}$ Oncol 15: 595-599, 1999

60. Sunderkötter C, Steinbrink K, Goebeler M, Bhardwaj R, Sorg $C$ : Macrophages and angiogenesis. J Leukoc Biol 55: 410-422, 1994

61. Torisu H, Ono M, Kiryu H, Furue M, Ohmoto Y, Nakayama J, Nishioka Y, Sone S, Kuwano M: Macrophage infiltration correlates with tumor stage and angiogenesis in human malignant melanoma: possible involvement of TNFalpha and IL-1alpha. Int J Cancer 85: 182-188, 2000

62. Varney ML, Johansson SL, Singh RK: Tumour-associated macrophage infiltration, neovascularization and aggressiveness in malignant melanoma: role of monocyte chemotactic protein1 and vascular endothelial growth factor-A. Melanoma Res 15 : 417-425, 2005

63. Whiteside TL: Signaling defects in T lymphocytes of patients with malignancy. Cancer Immunol Immunother 48: 346-352, 1999

64. Zou W: Immunosuppressive networks in the tumour environment and their therapeutic relevance. Nat Rev Cancer 5:263274,2005 